\title{
Staff perceptions of using outcome measures in stroke rehabilitation
}

\author{
Louisa-Jane Burton ${ }^{1,2}$, Sarah Tyson² \& Alison McGovern \\ 'Greater Manchester \& Cheshire Cardiac and Stroke Network, Stroke Rehabilitation Programme, Stockport, Manchester, UK \\ and ${ }^{2}$ School of Health Sciences, University of Salford, Salford, UK
}

\begin{abstract}
Purpose: The use of standardised outcome measures is an integral part of stroke rehabilitation and is widely recommended as good practice. However, little is known about how measures are actually used or their impact. This study aimed to identify current clinical practice; how healthcare professionals working in stroke rehabilitation use outcome measures and their perceptions of the benefits and barriers to use. Method: Eighty-four Health Care Professionals and 12 service managers and commissioners working in stroke services across a large UK county were surveyed by postal questionnaire. Results: Ninety-six percent of clinical respondents used at least one measure, however, less than half used measures regularly during a patient's stay. The mean number of tools used was $3.2(S D=1.9)$. Eighty-one different tools were identified; 16 of which were unpublished and unvalidated. Perceived barriers in using outcome measures in day-to-day clinical practice included lack of resources (time and training) and lack of knowledge of appropriate measures. Benefits identified were to demonstrate the effectiveness of rehabilitation interventions and monitor patients' progress. Conclusions: Although the use of outcome measures is prevalent in clinical practice, there is little consistency in the tools utilised. The term "outcome measures" is used, but staff rarely used the measures at appropriate time points to formally assess and evaluate outcome. The term "measurement tool" more accurately reflects the purposes to which they were put and potential benefits. Further research to overcome the barriers in using standardised measurement tools and evaluate the impact of implementation on clinical practice is needed.
\end{abstract}

Keywords: measurement, outcome measures, stroke, staff perceptions

\section{Introduction}

Stroke is the biggest cause of adult disability in the developed world, with around 110000 new cases each year and

\section{Implications for Rehabilitation}

- Health professionals working in stroke rehabilitation should work together to agree when and how outcome measures can be most effectively used in their service.

- Efforts should be made to ensure that standardised tools are used to measure outcome at set time-points during rehabilitation, in order to achieve the anticipated benefits.

- Communication between service providers and commissioners could be improved to highlight the barriers in using standardised measures of outcome.

approximately 300000 people living with moderate to severe disability as a result of the condition in England alone [1]. A key recommendation in clinical guidelines is the use of standardised outcome measures and assessment tools to measure changes in response to rehabilitation interventions $[2,3]$, to the extent that it has been advocated across the National Health Service (NHS) since 2008 [4]. In response to this policy drive, the use of outcome measures has become increasingly prevalent. Most previous work on the utilisation of outcome measures has been in neurological rehabilitation centres, which have shown a steady increase in the number of units using one or more standardised measures of outcome from $77 \%$ in 1997 to $86 \%$ in 2006 [5,6]. The Barthel Index [7] is the most commonly used measure in UK and European rehabilitation settings $[6,8]$, however, there is a lack of consensus on which other measures to use in both clinical and research settings [8,9], and many in clinical use are "home grown" and both unpublished and unvalidated [8].

In an effort to understand uptake in clinical practice, several studies have explored Health Care Professionals' (HCPs) perceptions of the benefits and barriers of using standardised outcome measures. Although often limited to

Correspondence: Louisa-Jane Burton, Greater Manchester \& Cheshire Cardiac and Stroke Network, Stroke Rehabilitation Programme, $9^{\text {th }}$ Floor Regent House, Heaton Lane, Stockport, UK, SK4 1BS. Tel.: 044161426 5912. E-mail: LouisaBurton@nhs.net

(Accepted) 
a single discipline [10-13], they have identified that the perceived benefits include helping to direct the plan of care [11], monitoring patients' progress and effectiveness of treatment [8], and enhancing communication with the patient [11] and with other HCPs [12]. Several barriers to use in clinical practice have also been consistently identified. Most are staffrelated and include a lack of familiarity with the measures and lack of knowledge about the appropriate measures to use $[10,12,14,15]$, lack of time to administer, score and interpret measures $[14,15]$ and absence of a clear purpose for measurement [15]. The cost of resources needed to collect outcome measures data is also perceived to be a barrier [16,17], including initial purchase and additional staffing to administer the measure [17]. Perceived patient-related barriers include measures being confusing and time-consuming for patients to complete [11] or unsuitable for people with some difficulties, such as communication or cognitive limitations [18].

Despite the political drive to introduce standardised outcome measures, there have been few studies to characterise how such measures are used in everyday clinical practice or to evaluate their impact and previous work has focused on identifying which measures are used across rehabilitation centres or departments as a whole $[5,6,8,14,19,20]$, or within a single profession [14]. We aimed to explore the use of standardised outcome measures across disciplines in stroke rehabilitation services in a large UK county, as part of a programme of work to examine the effects of implementing outcome measures into clinical practice. Rehabilitation professionals specifically working in stroke rehabilitation were surveyed along with service managers and commissioners, to identify when and how outcome measures are employed, and perceptions of benefits and barriers to their use in clinical practice.

\section{Method}

A survey design was employed. A questionnaire was formatted using open and closed questions with items identified from a review of the literature (See Appendix 1), consultations with HCPs working in stroke rehabilitation, and commissioners of stroke care. Open-ended questions were used where possible to encourage respondents to contribute further thoughts. The content and format were piloted with HCPs and commissioners in the stroke rehabilitation advisory group of the Greater Manchester \& Cheshire Cardiac and Stroke Network. Members were asked to review the questionnaire and comment on the representativeness of the questions, as well as the format and presentation, in order to establish face and content validity.

Inclusion criteria were to be a HCP, service commissioner or service manager working in a stroke rehabilitation service. As concerns were raised during piloting the questionnaire about the difficulty of gaining responses from NHS staff, particularly in the current economic climate, every effort was made to ensure anonymity to encourage the best response. As a result, the response rate could not be tracked. Fifteen hard (paper) copies were distributed to each of the 11 NHS stroke rehabilitation units situated in a large UK county, a total of 165 questionnaires. In each unit, a nominated person was responsible for distribution of the questionnaires within their team and returning them to the authors. The nominated staff were also sent electronic copies of the questionnaire and encouraged to use cascade and snowballing techniques for distribution (such as photocopying and e-mailing the questionnaire to colleagues) to ensure that they were distributed to as many members of stroke rehabilitation staff as possible. Reminders and further copies of the questionnaires were distributed through the nominated personnel and the authors' contacts with individual team members over a 3-month period, until no further responses were forthcoming. Data from the questionnaires were analysed using descriptive statistics with SPSS Statistics 17.0. Qualitative data were analysed using themed content analysis.

\section{Results}

Ninety-six questionnaires were returned. Due to the need to anonymise responses, response rate could not be tracked, although 165 paper questionnaires were distributed. Respondents included all members of the core stroke multidisciplinary team (MDT): Physiotherapists ( $\mathrm{n}=30,31 \%)$, Occupational Therapists $(\mathrm{n}=20,21 \%)$, Speech \& Language Therapists $(\mathrm{n}=10,10 \%)$, nurses $(\mathrm{n}=14,15 \%)$, physicians $(\mathrm{n}$ $=5,5 \%)$, psychologists $(n=1,1 \%)$, social workers $(n=1,1 \%)$, counsellors $(n=1,1 \%)$, a dietician $(n=1,1 \%)$ and an orthoptist $(n=1,1 \%)$. Twelve percent was primarily a service manager $(n=7,7 \%)$ or service commissioner $(n=5,5 \%)$. Results from these respondents will be considered separately, as they would not be expected to use outcome measures in their daily practice; however their opinions on the subject of outcome measurement are relevant. Of the 84 respondents working in clinical services, over half worked in both acute and rehabilitation $(58 \%, n=49), 7 \%$ worked only in acute services $(n=6)$ and $25 \%$ worked only in rehabilitation $(n=21)$. No response to this question was given by the remaining $10 \%(\mathrm{n}=8)$. Half worked in in-patient services $(50 \%, \mathrm{n}=42)$, and $23 \%$ worked in community services at least some of the time $(n=19)$. A further $23 \%$ did not respond to this question $(n=19)$.

Ninety-six percent used at least one outcome measure in their practice $(\mathrm{n}=81)$. The mean number of tools used was $3.2(\mathrm{SD}=1.9)$ with similar numbers used by the professions of the core MDT (mean of 2-4 measures, Table I). Professionals outside of the core MDT tended to use more measures (4-6, Table I). Eighty-one different tools were reported, comprising 65 published standardised measures and 16 home-grown or unnamed measures (for example 'depression scores' or 'patient goals'). The most frequently reported measures were the Barthel Index [7] (56\%, $\mathrm{n}=47)$, Berg Balance Scale [21] (23\%, $\mathrm{n}=19)$, Modified Rankin Scale [22] (15\%, n = 13), National Institute of Health Stroke Scale [23] (NIHSS; 12\%, $\mathrm{n}=10$ ) and Nine-Hole Peg Test [24] $(8 \%, \mathrm{n}=7)$. Of the 81 respondents using measures, $88 \%$ used at least one measure on admission and discharge from the stroke unit $(\mathrm{n}=71)$, however less than half $(47 \%, \mathrm{n}=38)$ used them regularly (on a weekly or fortnightly basis). Twelve percent of respondents used measures only once during a patient's stay $(\mathrm{n}=10)$. However, there were marked differences between the professions; $77 \%$ of nurses 
Table I. Use of measures by professional background.

\begin{tabular}{|c|c|c|c|c|c|}
\hline \multirow{2}{*}{$\begin{array}{l}\text { Profes- } \\
\text { sional } \\
\text { background }\end{array}$} & \multirow{2}{*}{$\begin{array}{l}\text { Frequency } \\
(\mathrm{n}=84)\end{array}$} & \multicolumn{2}{|c|}{$\begin{array}{l}\text { Mean number of } \\
\text { measures reported }\end{array}$} & \multicolumn{2}{|c|}{$\begin{array}{c}\text { Number of respondents } \\
\text { using Barthel Index }\end{array}$} \\
\hline & & Mean & $\mathrm{SD}$ & $\mathrm{n}$ & $\%$ \\
\hline $\begin{array}{l}\text { Physio- } \\
\text { therapist }\end{array}$ & 30 & 3.6 & 1.9 & 17 & 57 \\
\hline Physician & 5 & 4 & 1.9 & 3 & 60 \\
\hline $\begin{array}{l}\text { Occu- } \\
\text { pational } \\
\text { Therapist }\end{array}$ & 20 & 2.4 & 1.4 & 14 & 70 \\
\hline $\begin{array}{l}\text { Speech and } \\
\text { Language } \\
\text { Therapist }\end{array}$ & 10 & 2.2 & 1.9 & 3 & 30 \\
\hline $\begin{array}{l}\text { Psycholo- } \\
\text { gist }\end{array}$ & 1 & 4 & 0 & 0 & 0 \\
\hline $\begin{array}{l}\text { Social } \\
\text { Worker }\end{array}$ & 1 & 0 & 0 & 0 & 0 \\
\hline Nurse & 14 & 3.9 & 2.2 & 9 & 64 \\
\hline Counsellor & 1 & 6 & 0 & 0 & 0 \\
\hline Dietician & 1 & 4 & 0 & 1 & 100 \\
\hline Orthoptist & 1 & 4 & 0 & 0 & 0 \\
\hline Total/Mean & 84 & 3.2 & 1.9 & 47 & 55 \\
\hline
\end{tabular}

$(n=13)$ and $60 \%$ of physicians $(n=5)$ used at least one measure weekly, compared with only $35 \%$ of occupational therapists $(\mathrm{n}=20), 33 \%$ of physiotherapists $(\mathrm{n}=10)$ and $33 \%$ of speech and language therapists $(n=9)$. Unsurprisingly for a measure of independence in the activities of daily living, $70 \%$ of occupational therapists $(\mathrm{n}=14)$ used the Barthel Index, however, more than $50 \%$ of physiotherapists $(\mathrm{n}=17)$, physicians $(\mathrm{n}=3)$ and nurses $(n=9)$ and $30 \%$ of speech therapists also used it $(n=3)$.

\section{Perceptions of benefits and barriers to using outcome measures}

The most frequently reported benefit of the use of standardised outcome measures was to demonstrate the effectiveness of rehabilitation (85\%, Table II). Over half indicated benefits in monitoring patients' progress, planning rehabilitation effectively and helping to direct the plan of care. Generally, there was agreement between HCPs and service managers and commissioners regarding the benefits. The only area where the two groups varied was in the area of enhanced communication within the MDT and between HCPs, with $67 \%$ of the managers and commissioners indicating that they felt this was a benefit, compared with only $37 \%$ of HCPs.

The most frequent barrier to using standardised outcome measures for clinicians $(n=84)$ was resource limitations. This included lack of time, both to complete them $(63 \%, \mathrm{n}=53)$ and score them $(37 \%, \mathrm{n}=31)$, lack of training on how to use the measures $(46 \%, n=39)$ and lack of other resources $(43 \%$, $\mathrm{n}=36)$. Lack of familiarity with measures $(56 \%, n=47)$, and lack of consensus amongst the team about which tools to use $(57 \%, \mathrm{n}=48)$ were also problems. Service managers and commissioners $(n=12)$ agreed with the HCPs that major barriers were a lack of familiarity with measures $(67 \%, n=8)$, training in how to use them $(50 \%, \mathrm{n}=6)$ and consensus about which to use $(42 \%, n=5)$. However, less than a third perceived lack of resources to be a problem. The following additional
Table II. Perceived benefits of using standardised outcome measures.

\begin{tabular}{|c|c|c|c|c|}
\hline & \multicolumn{2}{|c|}{$\operatorname{HCPs}(\mathrm{n}=84)$} & \multicolumn{2}{|c|}{$\begin{array}{c}\text { Managers and } \\
\text { commissioners }(\mathrm{n}=12)\end{array}$} \\
\hline & $\mathrm{n}$ & $\%$ & $\mathrm{n}$ & $\%$ \\
\hline $\begin{array}{l}\text { Demonstrate } \\
\text { effectiveness of } \\
\text { rehabilitation }\end{array}$ & 71 & 85 & 10 & 83 \\
\hline Monitor patient progress & 64 & 76 & 7 & 58 \\
\hline $\begin{array}{l}\text { Help direct the plan of } \\
\text { care }\end{array}$ & 44 & 52 & 8 & 67 \\
\hline $\begin{array}{l}\text { Plan rehabilitation } \\
\text { intervention effectively }\end{array}$ & 45 & 54 & 7 & 58 \\
\hline $\begin{array}{l}\text { Enhance communica- } \\
\text { tion within MDT/other } \\
\text { HCPs }\end{array}$ & 31 & 37 & 8 & 67 \\
\hline $\begin{array}{l}\text { Identify the patient's } \\
\text { problems }\end{array}$ & 30 & 36 & 5 & 42 \\
\hline $\begin{array}{l}\text { Help focus the } \\
\text { intervention }\end{array}$ & 31 & 37 & 5 & 42 \\
\hline $\begin{array}{l}\text { Help motivate the } \\
\text { patient }\end{array}$ & 28 & 33 & 4 & 33 \\
\hline $\begin{array}{l}\text { Enhance } \\
\text { communication with the } \\
\text { patient }\end{array}$ & 27 & 32 & 4 & 33 \\
\hline $\begin{array}{l}\text { Enhance } \\
\text { communication with } \\
\text { patients' family }\end{array}$ & 23 & 27 & 2 & 17 \\
\hline $\begin{array}{l}\text { Comply with clinical } \\
\text { guidelines }\end{array}$ & 15 & 18 & 2 & 17 \\
\hline Other & 0 & 0 & 0 & 0 \\
\hline
\end{tabular}

HCP, Health Care Professional; MDT, multidisciplinary team.

barriers were also noted: Patient impairments, e.g. cognitive and language problems prevent the use of measures $(n=4)$; staff forgetting to use measures $(n=2)$; concerns about the reliability and sensitivity of measures $(n=4)$; lack of patient engagement if the tool is seen to be separate from treatment $(\mathrm{n}=1)$.

Thirty-six respondents made further comments about the use of outcome measures in the following additional themes:

- Difficulties finding suitable measures for specific impairments $(\mathrm{n}=15)$ or for use across both health and social care $(\mathrm{n}=2)$.

- Lack of standardisation and consensus on which measures to use, both locally and at national level $(\mathrm{n}=7)$.

- The challenges of using and sharing measures within a multidisciplinary context $(\mathrm{n}=2)$ and within individual disciplines $(\mathrm{n}=2)$.

- Needs for service improvement and requests for advice on selecting measures $(\mathrm{n}=4)$.

\section{Discussion}

The findings of this study indicate that outcome measures are commonly used in stroke rehabilitation; slightly more frequently than previous recent reports from similar rehabilitation contexts [6] and in line with recent national guidance advocating their use $[2,3]$. The current political context which focuses on efficiency savings within UK public services 
may also have had an impact, with clinicians keen to obtain objective data to demonstrate the effectiveness of services. Although the use of outcome measures was commonplace, a wide variety of measures was used and many were nonstandardised 'home-grown' measures with no evidence of the psychometric properties. This lack of consensus shows little progress from previous reports 10 years ago $[8,19]$ and may, at least in part, be due to the range of tools available. Some respondents may also have been using a standardised assessment but not known the name and so used a generic term such as 'depression score.' Although national guidance in England and many other countries advocates the use of measures of outcome, it does not mandate specific tools to be used for this purpose. Now the principle of using objective measures seems to be accepted and commonplace, further development of the guidelines to contain more specific guidance and recommendations may improve this situation.

The most frequently used outcome measure was the Barthel Index, employed by $56 \%$ of clinical respondents, in line with findings from a previous report of neurological rehabilitation centres in the UK, which found that $59 \%$ of centres utilised this measure [6]. Previous work has, however, not considered the use of measures across specific disciplines and the finding that $30 \%$ of speech and language therapists reported using the Barthel Index is surprising as the tool does not include any measurement of communication. However, it is the preferred measure of independence in activities of daily living [3] and so speech and language therapists may be using it as part of the MDT rather than as a measure of their specific input, which may indicate the MDT members surpassing their traditional professional boundaries to provide inter-disciplinary patient (rather than profession) focussed care. As the primary aim of rehabilitation is to reduce activity limitations in daily life, measurement of outcomes at this level is appropriate, with all members of the multidisciplinary teams contributing to patient progress and utilising the same measures to document this. However, discipline-specific measures of particular impairments are also valuable for diagnostic purposes and to plan and monitor treatment, but are unlikely to be used in a multidisciplinary context, as they would involve information which would not be relevant to the whole team. Therapeutic interventions are often directed towards a primary impairment and therefore, impairment-based outcome measures would be appropriate to assess whether the intervention has been effective [25]. Although the use of discipline-specific measures is likely to have contributed to the wide variety of measures reported by stroke rehabilitation professionals in this survey, the results indicate that a number of tools are being used to measure the same impairment. For example, six different measures of balance were reported, suggesting a lack of consensus amongst members of a single discipline.

The perceived benefits to using outcome measures were similar to previous studies, and focused on demonstrating the effectiveness of rehabilitation and monitoring patient progress [11]. A recent observational study of rehabilitation MDTs suggested that using standardised measures can go beyond this and promote a shared understanding of patients' problems within MDT meetings, thus enhancing team communication and providing a common ground for patient-centred discussion [26-28]. However, only a third of HCPs in this survey perceived enhanced communication to be a benefit. This may be due to the fact that HCPs were simply unaware of the effect on communication, or that they used the measures in a different, less effective way to the neurological rehabilitation team observed by Greenhalgh et al. [26-28]. Despite the policy drive to use standardised assessment tools, there has been little research to examine how measures are actually used or how their use interfaces with other assessment and clinical processes (such as goal setting and treatment or discharge planning). Nor is it clear what impact, if any, they have on service delivery or clinical outcomes. Further research to explore these issues is indicated.

This study adds to previous work through considering the detail of how outcome measures are used during stroke rehabilitation, staff perceptions of their use and benefits, and whether the use of measures at different time-points is effective in achieving the anticipated benefits. Whilst most respondents used at least one measure on admission and discharge, only $47 \%$ used a measure regularly (weekly or fortnightly) and some $(12 \%)$ took measurements only once (either on admission or on discharge). If the measures were taken only once, it is not possible that they were used to monitor progress or to demonstrate effectiveness as perceived by most of the respondents. National guidelines recommend that changes in patient functioning should be measured at appropriate intervals and that standardised tools should be used $[3,29]$. However, there is no detail about which measures should be used, or how often. Some respondents may have been using the measures in a way which enabled national recommendations to be met (and a high score in the national audits to be achieved; the so-called tick-box approach) but have little impact on clinical practice. More specific recommendations and audit standards would be beneficial; as would further research to establish the optimal way to implement outcome measures in clinical practice.

The term "outcome measure" was deliberately left undefined in our questionnaire instrument as we wanted to elicit a broad view of staff perceptions, and throughout the survey, as in clinical practice, the term "outcome measure" was used synonymously with "measurement tool”, or "assessment measure". While an outcome measure is designed to be a measure of change as a result of intervention at the end of the intervention or episode of care, standardised measurement tools may be used for a variety of purposes such as screening (early identification of those at high risk of specific problems), assessment (identification of a patient's impairments and activity limitations) or classification (to predict outcome based on the severity of impairments or activity limitations) [30]. The results of this survey suggest that HCPs are using measurement tools rather than outcome measures. More specific measurements need to be taken during and at the end of episodes of care to assess outcome and awareness of the distinction between the terms and consistent use of language would prevent confusion.

The wide use of "home-grown" non-standardised outcome measures and lack of knowledge about which 
measures to use and how to use and interpret them demonstrated in the results of this study is cause for concern as the advantages of using standardised over non-standardised measures are well-documented, and include benefits in reducing repetition of assessments when patients transfer between services and allowing quality comparisons of different services to be made [20,31]. For clinicians to have confidence that the tools they are using will achieve the anticipated benefits, measures must have been subject to reliability and validity testing within the post-stroke population, and administered and scored in accordance with standardised instruction manuals [20]. This is true whether the measure is used to "diagnose" impairment or to monitor patient progress; clinicians need to be confident that the tool used is sensitive and specific enough to detect impairments and that changes in scores over time are a result of genuine improvements in ability or performance. However, it is time-consuming to explore the research literature to identify which tools produce the most robust data and more than half of respondents indicated a lack of awareness of appropriate measures. Further education, more specific recommendations and requirements for local and national auditing systems may facilitate the migration from homegrown to standardised measures.

The main limitation of this study rests in its reliance on reported, rather than observed behaviours and so social desirability bias may be present, with clinicians over-reporting use of measures in line with national recommendations. As the sample was limited to one county in the UK and a relatively small number of professionals from each discipline were surveyed, then generalisability may be limited. However, the composition of the sample reflects the make-up of stroke rehabilitation services across the UK and internationally, and we involved the staff in all of the stroke rehabilitation units $(\mathrm{n}=11)$ in one of the largest conurbations in the UK (serving a population of approximately 3 million); as such we are confident that the results are representative of other stroke units with a similar healthcare system. Strength of the study was its consideration of the views of both the MDT and those involved in service management and commissioning.

This study has raised issues in the differences in perceptions of service managers and commissioners and those of clinicians regarding the benefits and barriers to the use of outcome measures, which could be further explored in future research to help eliminate the barriers to using measures in clinical practice. Our findings indicate that whilst the majority of managers and commissioners felt that measures could be effectively used to plan rehabilitation and enhance communication between HCPs, fewer rehabilitation professionals perceived these to be benefits. Service commissioners and managers also did not feel that a lack of resources, such as training and time to complete measures, was a barrier to the use of outcome measures to the same extent that clinicians did. Further research is needed to explore improvements to the communication process between clinicians and service managers and commissioners with regard to the use of measures.

\section{Acknowledgements}

The authors would like to thank the staff at Bolton Hospital NHS Foundation Trust, Central Manchester University Hospital NHS Foundation Trust, Pennine Acute Hospital NHS Trust, Salford Royal NHS Foundation Trust, Stockport NHS Foundation Trust, Tameside Hospital NHS Foundation Trust, Trafford Healthcare NHS Trust, University Hospital of South Manchester NHS Foundation Trust and Wrightington, Wigan and Leigh NHS Foundation Trust for their participation.

Declaration of Interest: This project has been funded through a Knowledge Transfer Partnership (grant number 0007812), funded by the Technology Strategy Board and the Greater Manchester \& Cheshire Cardiac and Stroke Network.

\section{References}

1. National Audit Office. Progress in improving stroke care. London: The Stationery Office; 2010.

2. Department of Health. National stroke strategy. London: Her Majesty's Stationery Office; 2007.

3. Intercollegiate Stroke Working Party. National Clinical Guideline for stroke, 3rd Ed. London: Royal College of Physicians; 2008.

4. Darzi A. High quality care for all. London: Department of Health; 2008.

5. Turner-Stokes L, Turner-Stokes T. The use of standardized outcome measures in rehabilitation centres in the UK. Clin Rehabil 1997;11:306-313.

6. Skinner A, Turner-Stokes L. The use of standardized outcome measures in rehabilitation centres in the UK. Clin Rehabil 2006;20:609-615.

7. Mahoney FI, Barthel DW. Functional evaluation: the barthel index. Md State Med J 1965;14:61-65.

8. Torenbeek M, Caulfield B, Garrett M, Van Harten W. Current use of outcome measures for stroke and low back pain rehabilitation in five European countries: first results of the ACROSS project. Int J Rehabil Res 2001;24:95-101.

9. Duncan PW, Jorgensen HS, Wade DT. Outcome measures in acute stroke trials: a systematic review and some recommendations to improve practice. Stroke 2000;31:1429-1438.

10. Copeland JM, Taylor WJ, Dean SG. Factors influencing the use of outcome measures for patients with low back pain: a survey of New Zealand physical therapists. Phys Ther 2008;88:1492-1505.

11. Jette DU, Halbert J, Iverson C, Miceli E, Shah P. Use of standardized outcome measures in physical therapist practice: perceptions and applications. Phys Ther 2009;89:125-135.

12. Swinkels RA, van Peppen RP, Wittink H, Custers JW, Beurskens AJ. Current use and barriers and facilitators for implementation of standardised measures in physical therapy in the Netherlands. BMC Musculoskelet Disord 2011;12:106.

13. van Peppen RPS. Towards evidence-based physiotherapy for patients with stroke. PhD Thesis. Utrecht University \& Hogeschool Utrecht; 2008.

14. Abrams D, Davidson M, Harrick J, Harcourt P, Zylinski M, Clancy J. Monitoring the change: current trends in outcome measure usage in physiotherapy. Man Ther 2006;11:46-53.

15. Stokes EK, O'Neill D. Use of outcome measures in physiotherapy practice in ireland from 1998 to 2003 and comparison to Canadian trends. Physiother Can 2008;60:109-116.

16. Fung $\mathrm{CH}$, Hays RD. Prospects and challenges in using patient-reported outcomes in clinical practice. Qual Life Res 2008;17:1297-1302.

17. Zimmerman M, Chelminski I, Young D, Dalrymple K. Using outcome measures to promote better outcomes. Clin Neuropsychiatry 2011;8:28-36.

18. Bausewein C, Simon ST, Benalia H, Downing J, Mwangi-Powell FN, Daveson BA, Harding R, Higginson IJ; PRISMA. Implementing patient reported outcome measures (PROMs) in palliative care-users' cry for help. Health Qual Life Outcomes 2011;9:27.

19. Haigh R, Tennant A, Biering-Sørensen F, Grimby G, Marincek C, Phillips S, Ring H, et al. The use of outcome measures in physical medicine and rehabilitation within Europe. J Rehabil Med 2001;33:273-278.

20. Chesson R, Macleod M, Massie S. Outcome measures used in therapy departments in Scotland. Physiotherapy 1996;82:673-679. 
21. Berg K, Wood-Dauphinee S, Williams JI, Gayton D. Measuring balance in the elderly: preliminary development of an instrument. Physiother Can 1989;41:304-331.

22. van Swieten JC, Koudstaal PJ, Visser MC, Schouten HJ, van Gijn J. Interobserver agreement for the assessment of handicap in stroke patients. Stroke 1988;19:604-607.

23. Brott T, Adams HP Jr, Olinger CP, Marler JR, Barsan WG, Biller J, Spilker $\mathrm{J}$, et al. Measurements of acute cerebral infarction: a clinical examination scale. Stroke 1989;20:864-870.

24. Mathiowetz V, Weber K, Kashman N, Volland G. Adult norms for the nine hole peg test of finger dexterity. Occup Ther J Res 1985;5:24-38.

25. Wade DT. Outcome measures for clinical rehabilitation trials: impairment, function, quality of life, or value? Am J Phys Med Rehabil 2003;82:S26-S31.

26. Greenhalgh J, Flynn R, Long AF, Tyson S. Tacit and encoded knowledge in the use of standardised outcome measures in multidisciplinary team decision making: a case study of in-patient neurorehabilitation. Soc Sci Med 2008;67:183-194.

27. Tyson S, Greenhalgh J, Long AF, Flynn R. The use of measurement tools in clinical practice: an observational study of neurorehabilitation. Clin Rehabil 2010;24:74-81.

28. Tyson SF, Greenhalgh J, Long AF, Flynn R. The influence of objective measurement tools on communication and clinical decision making in neurological rehabilitation. J Eval Clin Pract 2012;18:216-224.

29. Royal College of Physicians. National Sentinel Stroke Clinical Audit 2010 Round 7: Public report for England, Wales and Northern Ireland. Prepared on behalf of the Intercollegiate Stroke Working Party. London: RCP; 2010.

30. Sullivan JE, Andrews AW, Lanzino D, Perron AE, Peron A, Potter KA. Outcome measures in neurological physical therapy practice: part II. A patient-centered process. J Neurol Phys Ther 2011;35:65-74.

31. Zinober BW. Which outcome measure? Physiotherapy 1995;81:185-186.

\section{Appendix 1. Outcome Measures Questionnaire}

As part of the work to improve stroke rehabilitation, we would like you to complete this short questionnaire, which is the start of a 3-year project to design and implement a comprehensive toolkit of outcome measures into stroke rehabilitation (G-MASTER).

This questionnaire is for professionals working in stroke services to establish your feelings about using outcome measures and identify which outcome measures are currently in use. Information from your responses will be used to develop the outcome measures toolkit and help us identify strategies to address barriers within the implementation stage of the project. Please be assured that your responses will be kept confidential and it will not be possible to identify you from the responses that you give.

Thank you for your participation.

1. Which outcome measures do you routinely collect in your clinical practice? Please print the name of the each measure and tick the relevant box to indicate how frequently you complete the measure for each individual patient.

\begin{tabular}{|l|l|l|l|l|l|l|}
\hline Measure & Admission & Discharge & Admission \& Discharge & Weekly & Fortnightly & Other \\
\hline & & & & & & \\
\hline \\
\hline
\end{tabular}

Please state "other" frequency below:

2. Please indicate the top five benefits of using outcome measures in stroke rehabilitation by placing ticks in the relevant boxes.

$\square$ Demonstrate effectiveness of rehabilitation

Enhance communication with the patient

Enhance communication within multidisciplinary team/other healthcare professionals

$\square$ Enhance communication with patients' family

Help direct the plan of care

Identify the patient's problems

$\square$ Plan rehabilitation intervention effectively

$\square$ Monitor patient progress

$\square$ Help focus the intervention

$\square$ Help motivate the patient

$\square$ Comply with clinical guidelines

Other, please state: 
3. Please indicate the top five barriers that would prevent you from using outcome measures in your current practice by placing ticks in the relevant boxes.

$\square$ They take too much time to complete

$\square$ It takes too long to work out the scores after filling in

$\square$ Lack of resources (e.g. money, room space)

$\square$ Lack of familiarity with outcome measures

$\square$ Lack of training on how to use outcome measures

$\square$ No appropriate tools available

$\square$ Lack of consensus amongst team about which tools to use

$\square$ Against the use of outcome measures (please give details in the 'further comments' space provided on the next page)

Other, please state:

4. If you have any further comments about the use of outcome measures within your stroke rehabilitation service, please provide them below:

\section{Demographic questions}

Please indicate your area of work (tick more than one if applicable):

$\square$ Community

$\square$ In-Patient Services

$\square$ Out-Patient Services

$\square$ Acute

$\square$ Rehabilitation

$\square$ Other, please state

Please indicate your profession:

$\square$ Physiotherapist

$\square$ Physician

$\square$ Service Manager

$\square$ Occupational Therapist

$\square$ Speech and Language Therapist

$\square$ Psychologist

$\square$ Service Commissioner

$\square$ Social Worker

$\square$ Nurse

$\square$ Rehabilitation Assistant

$\square$ Other, please state 